\title{
FORMAÇÃO CONTINUADA DE PROFESSORES: ANÁLISES DE UMA EXPERIÊNCIA VIVIDA EM UMA ESCOLA MUNICIPAL DO NOROESTE PAULISTA.
}

Izabella Alvarenga Silva, Luciana Aparecida Nogueira da Cruz, Raul Aragão Martins.

Universidade Estadual Paulista - UNESP, Doutorado em Educação, Presidente Prudente, SP. E-mail: izabella.silva@gmail.com.Agência de fomento: CAPES.

\section{RESUMO}

Trabalhar com questões éticas e morais na escola ainda é um desafio para os profissionais da área da Educação. Professores e gestores reafirmam a importância da formação inicial e continuada, para lidar com as dificuldades diárias da escola. Nesse sentido, nosso objetivo é apresentar considerações sobre uma atividade de formação continuada realizada em uma escola pública. A pesquisa é qualitativa, de natureza aplicada e tem caráter descritivo. Os dados apresentados são oriundos do processo formativo realizado com 24 professores ao longo de 14 meses. Os instrumentos utilizados foram: questionário, observação e entrevista. A análise dos dados foi feita por meio da análise de conteúdo. Como resultados, prevaleceu a culpabilização da família em relação aos problemas cotidianos vividos na instituição, idealização de um aluno obediente e disciplinado, ausência da equipe gestora na formação e mudanças em seu cronograma. Concluímos que a formação continuada na escola encontrou relativa resistência por parte dos participantes.

Palavras-chave: Formação continuada. Desenvolvimento moral. Educação moral. Formação de professores. Ensino fundamental

\section{CONTINUED TEACHER FORMATION: ANALYSIS OF A REAL EXPERIENCE IN A MUNICIPAL SCHOOL AT THE NORTHWEST OF SÃO PAULO.}

\begin{abstract}
It's still a challenge for education professionals to work with ethic and moral issues in school environment. Teachers and managers reaffirm the importance in initial and continued formation, in order to deal with daily difficulties of the school environment. In this sense, our goal is to present considerations about a continued formation activity realized in a public school. The research is qualitative, with applied nature and has descriptive character. The presented data come from the formational process applied at 24 teachers over 14 months. The instruments used were: quiz, observation and interview. The data analysis was made through the content analysis. As results, prevailed the family blame in relation to everyday problems lived inside the institution, ideation of an obedient and disciplined student, absence of the manage crew in formation and changes on it's schedule. We concluded that the continued formation in school environment encountered relative resistance on the part of the participants.

Keywords: Continued formation. Moral development. Moral education. Teacher formation. Elementary school.
\end{abstract}




\section{INTRODUÇÃO}

A pesquisa que descrevemos aqui constitui uma intervenção realizada com professores de uma escola municipal dos anos finais do ensino fundamental. A intervenção consistiu em um curso de formação continuada organizada como uma atividade de extensão universitária, com carga horária de 60 horas e certificação da Unesp, os responsáveis pela sua execução são os autores deste trabalho.

A atividade formativa foi oferecida para todos os professores e gestores da escola, seu objetivo foi proporcionar oportunidade de estudo e reflexões sobre o desenvolvimento moral infantil e sobre o ambiente sociomoral proporcionado pela escola, a perspectiva teórica adotada na formação foi a teoria de Piaget (1930/1996, 1932/1994).

Piaget (1932/1994), autor amplamente estudado na área da Educação, criou uma teoria para explicar como o homem constrói estruturas mentais na interação com o meio físico e social, além disso, buscou explicar também o percurso que conduz este a ação moral. Suas conclusões indicam que, em relação ao desenvolvimento moral, o percurso é marcado por duas tendências morais, a heteronomia e a autonomia.

La Taille (1994), destaca o fato do desenvolvimento moral acontecer em paralelo ao desenvolvimento cognitivo, uma vez que elementos da teoria sobre a cognição como assimilação, acomodação, equilibração e egocentrismo estão presentes na teoria do desenvolvimento moral infantil. Outro pronto importante é a conclusão de que a ação precede a consciência, tal como o pensamento concreto precede o pensamento abstrato.

De acordo com Vinha e Mantovani de Assis (2005), a maioria dos professores, quando questionada, aponta como objetivo maior do seu trabalho formar estudantes autônomos, porém, muitos deles não se sentem seguros sobre como podem favorecer o desenvolvimento da moralidade de crianças e adolescentes. Diversos trabalhos alertam para o despreparo do professor e a dificuldade encontrada para trabalhar com a moralidade dos alunos (PICADO, ROSE, 2009; TOGNETA, VINHA, 2007; VINHA, 2000; VINHA, 2003).

Vinha e Mantovani de Assis (2005, p. 5) afirmam que as principais dificuldades dos professores em construírem um ambiente sociomoral propício à construção da autonomia são: compreensões fragmentárias da teoria, o anseio pelo controle e procedimentos disciplinares, o desconforto de aprender o novo, a educação fundamentada no senso comum, busca pela segurança e a imaturidade moral dos próprios educadores.

O processo formativo desenvolvido na escola buscou proporcionar o estudo da teoria piagetiana para que questões cotidianas que envolvessem regras, valores e princípios morais fossem problematizadas e refletidas pelos profissionais que ali trabalham. A superação da heteronomia moral só é possível com relações interpessoais baseadas na reciprocidade e no respeito mútuo, fato desconhecido por muitos educadores.

Paralelo a isso, entendemos que formação continuada é toda intervenção que provoca mudanças no comportamento, na informação, nos conhecimentos, na compreensão e nas atitudes dos professores em exercício (IMBERNÓN, 2010). Nesse sentido, tal processo, na sua essência, é construído a partir de uma constante reflexão do professor sobre sua prática, evidenciando seu caráter crítico, reflexivo e coletivo, uma vez que a escola, enquanto instituição, e os professores estão imersos em um determinado contexto.

Considerando a definição apresentada anteriormente, destacamos três pressupostos essenciais da atividade formativa oferecida aos professores: a) a formação deve oferecer condições para que o professor reflita sobre suas próprias concepções acerca do desenvolvimento moral infantil e do trabalho que a escola pode desenvolver neste processo, b) é necessário um espaço no qual ocorra uma reflexão sobre a ação dos professores e da escola enquanto instituição formativa, em relação ao desenvolvimento moral dos alunos, uma vez que as práticas geralmente adotadas pelas escolas não favorecem o desenvolvimento da autonomia moral, e c) a busca coletiva de 
alternativas para superar as dificuldades, sejam elas individuais e/ou coletivas, uma vez que o tema abordado pela formação continuada é novo para o grupo, e o ato de educar, de proporcionar intervenções, deve ser concebido como um processo de construção.

Assim, estabelecemos como objetivo desse texto apresentamos análises de alguns fatores que constituíram o processo de formação continuada, vivido na escola ao longo de quatorze meses.

\section{METODOLOGIA}

De acordo com Gil (2008), a pesquisa que apresentamos é de abordagem qualitativa, de natureza aplicada, tem caráter descritivo e delineamentos de um estudo de caso. A formação com vinte e quatro professores aconteceu em uma escola pública municipal, localizada em um pequeno município do noroeste paulista, entre os meses de março de 2015 e maio de 2016.

Considerando o espaço de que dispomos nesse texto para apresentarmos e discutirmos dados de pesquisa, optamos por restringirmos nossas análises aos fatores que tornaram a formação vivida diferente do processo que foi proposto inicialmente. Para a coleta dos dados, foram utilizados três instrumentos: questionário, observação e entrevista. As técnicas de estudo aplicadas aos dados apresentados nesse texto foram a análise de conteúdo, proposta por Bardin (1979). Por meio da análise de conteúdo, foi possível decompor em partes todo o material, fazer inferências e interpretar os resultados. Em síntese, inicialmente realizamos uma leitura atenta e minuciosa do material, exploramo-los na busca de sentidos mais amplos, ideias implícitas e, por fim, criamos uma síntese interpretativa.

Esta pesquisa foi submetida ao Comitê de Ética em Pesquisa da Faculdade de Filosofia e Ciências de Marília e recebeu parecer favorável para sua realização (CAAE: 38224914.6.0000.5406).

\section{RESULTADOS}

A atividade formativa teve um total de vinte encontros na escola. De uma forma geral, percebemos a dificuldade do grupo em abandonar o saudosismo das práticas educativas ocorridas no passado, como os castigos físicos, as punições severas e a expulsão de alunos indisciplinados. Tal postura é compreensível, como apresenta a literatura sobre formação de professores e o estudo de Vinha e Mantovani de Assis (2005). A seguir, faremos alguns apontamentos sobre o desenvolvimento da formação continuada oferecida na escola, como participação da gestão, mudança do cronograma, responsabilização das famílias e conscientização em relação ao ambiente sociomoral.

As gestoras raramente participavam dos encontros de formação. O convite para a participação na formação continuada foi direcionado à todos os professores e à equipe gestora da escola, acompanhado de argumentos que ressaltavam a importância da coesão do grupo para o bom andamento do trabalho. Dos 28 professores regularmente inscritos, 24 concluíram a formação. Em relação à equipe gestora, formada por quatro profissionais, apenas a coordenadora pedagógica participou da maioria dos encontros. A diretora, figura centralizadora de decisões e responsabilidades na instituição, participou muito pouco da formação, evidenciando seu distanciamento diante das questões que foram abordadas.

Os encontros de formação não aconteceram dentro da agenda planejada. Inicialmente, o combinado entre nós formadores e a escola era que os encontros com o grupo aconteceriam quinzenalmente, ao longo de todo o ano de 2015, para que a formação fosse concluída em dezembro do mesmo ano. No entanto, as datas foram modificadas pela gestão da escola em função de outros compromissos da instituição, como reunião de pais, formação da empresa fornecedora do material apostilado adotado, reuniões do conselho de classe, datas comemorativas, entre outros eventos. Tais modificações na agenda da formação geraram atraso no 
cronograma inicial, e as poucas datas disponibilizadas pela escola comprometeram, de certa forma, o caráter de continuidade das discussões iniciadas.

As falas de muitos professores durante os encontros de formação evidenciaram uma visão pautada no senso comum de que a educação moral "deve vir de casa", ou seja, é responsabilidade da família. Para os profissionais da educação que participaram da formação, o poder de fracassar ou obter sucesso na educação moral dos alunos está somente nas mãos da família. Aqueles considerados indisciplinados e que não respeitam as regras propostas pela escola são o reflexo da educação recebida em casa, ou seja, há um sentimento muito forte de culpabilização da família.

Notamos também, certa expectativa dos participantes do processo formativo ao esperarem que os alunos chegassem "prontos" à escola. A principal queixa compartilhada pelo grupo foi em relação à "falta de respeito dos alunos"; em seus discursos, os professores da escola demonstram esperar, ainda que veladamente, uma receita para solucionar tal problema de desrespeito pelas autoridades (os professores, os gestores e os pais). Os discursos sobre (des)respeito apontam nitidamente para um desejo de respeito unilateral, de obediência cega às regras. Havia total desconhecimento da necessidade de se construir relações reciprocas em que se estabelece o respeito mútuo, principalmente entre professor/adulto e aluno/criança/adolescente.

Sobre a conscientização em relação ao ambiente sociomoral proporcionado pela escola, no início do processo formativo notamos que os professores não eram conscientes deste aspecto, considerando a coerção e a cooperação como elementos constitutivos das relações interpessoais, conceitos estes trabalhados por Piaget (1932/1994). Ao final da formação, foi possível notar que o grupo estava mais consciente em relação a algumas práticas equivocadas adotadas pela escola, como o uso de filmadoras com objetivo de controlar o comportamento dos alunos e expor situações de conflitos aos pais, a suspensão como forma de punição e o autoritarismo presente nas relações.

\section{DISCUSSÃO}

Menin (2007) nos lembra que o trabalho com questões ética e morais dentro da escola não deve ser restrito apenas à situações ocorridas dentro da sala de aula, ficando apenas sob responsabilidade do docente; ao contrário, a instituição deve se responsabilizar pelo estudo, problematização e encaminhamento de situações cotidianas que interferem no desenvolvimento moral dos alunos, e a atuação da equipe gestora é fundamental neste processo. O fato de tal equipe não ter participado de forma efetiva do processo formativo, nos faz crer, que consideram o trabalho com questões morais no ambiente escolar inviável, o que, estudos e pesquisas na área da psicologia e educação moral apontam como grande equívoco.

Mudanças de agenda e cronograma são comuns em qualquer instituição educativa; eventos, reuniões extraordinárias e convocações acontecem ao longo do ano letivo. No entanto, o fato da formação ter acontecido em 14 meses, e não em nove como acordado no planejamento inicial, indica que a atividade formativa não foi incorporada, ou seja, "abraçada", pela escola como uma atividade institucional. No estudo de Vinha e Mantovani de Assis (2006), as autoras alertam que o tempo da formação é algo importante a se considerar, atividades muito breves ou muito extensas não são produtivas.

Assim como na pesquisa de Tardeli (2003), abordar o tema Respeito foi essencial na formação continuada, em razão das queixas apresentadas pelo grupo de professores sobre a falta de respeito por parte dos alunos. Nossa tentativa em desconstruir a ideia de que o respeito é algo "automático" exigiu vários encontros e proporcionou inúmeras discussões. Os dois tipos de respeito conceituados por Piaget (1932/1994) eram desconhecidos por todos os professores do grupo, tampouco a noção de respeito como um sentimento, pois prevalecia a concepção de respeito como sendo uma ação traduzida em obediência às regras e comandos. 
Identificamos relativo incômodo do grupo quando nossas intervenções apontaram para o fato de que muitos alunos também são desrespeitados pelos professores, funcionários e equipe gestora da escola, e que, certamente, o desrespeito não é uma queixa exclusiva do corpo docente naquela escola. Respeito mútuo e reciprocidade eram conceitos novos naquele contexto, jamais discutidos e/ou pensados pelos professores como via para solucionar suas queixas referentes ao desrespeito nas relações

A conscientização que buscamos proporcionar junto ao grupo de professores sobre o ambiente sociomoral constitui-se aspecto essencial do trabalho com o desenvolvimento moral dos alunos, de acordo com DeVries e Zan (1998). E consideramos ter alcançado uma "conscientização nascente". Nesse processo, surgiram dúvidas sobre o momento de trabalhar questões morais com os alunos, uma vez que há cobrança da gestão para o cumprimento do calendário das atividades curriculares, em função das avaliações (internas e externas) que os alunos devem fazer. Ao problematizar esse discurso de cumprir o currículo, mostramos que as questões morais não são menos importantes do que as questões curriculares e que os alunos, além das aulas e avaliações, devem ser colocados em situações de partilha e discussão de assuntos que interferem no dia a dia da escola.

\section{CONCLUSÃO}

O objetivo desse texto foi apresentar brevemente algumas análises feitas a partir da realização de uma formação com professores de uma escola pública dos anos finais do ensino fundamental, cujo objetivo foi problematizar e discutir o trabalho com questões morais na escola a partir da teoria do desenvolvimento moral de Piaget (1932/1994).

O processo formativo vivido na escola teve um total de vinte encontros, nos quais foram discutidas questões relativas ao desenvolvimento moral dos alunos, questões estas que fazem parte do cotidiano dos professores, como o modo de propor e trabalhar as regras, as punições adotadas pela instituição, a relação delicada entre família e escola e a importância de possibilitar o protagonismo juvenil.

De fato, a formação teria alcançado de forma mais efetiva seu objetivo se a equipe gestora tivesse participado de forma mais próxima, compartilhando dúvidas e posicionamentos, e se a agenda inicialmente proposta tivesse se concretizado, favorecendo a continuidade e a frequência das discussões. Verificamos uma espécie de "conscientização nascente" em relação ao ambiente sócio moral proporcionado pela escola, uma vez que educar o olhar e considerar a mudança de algumas práticas leva tempo e depende do estudo constante da teoria citada.

O trabalho com profissionais da área da Educação sobre autonomia moral, cooperação e relações interpessoais sustentadas pelo respeito mútuo permite à comunidade escolar a conquista de um novo modo de pensar o desenvolvimento infantil, no qual práticas coercitivas vão tornandose menos eficazes e usuais. E neste contexto de superar práticas equivocadas e conquistar outras, a figura do professor destaca-se, pelo alcance que possui na educação das crianças.

$\mathrm{Na}$ área da Educação, teorias estão disponíveis para a compreensão dos diferentes fatores que interferem no dia a dia da escola. A formação do profissional que ali trabalha, seja inicial ou continuada, presencial ou à distância, em grupo ou individual, pressupõe uma reflexão da ação e uma reflexão na ação, e, antes de tudo isso, disposição para reflexão.

A formação que nos empenhamos em oferecer encontrou resistência não porque privilegiamos uma teoria em detrimento de outras, mas porque apontamos que toda a escola, e não somente alguns profissionais que ali trabalham, deve engajar-se nas reflexões sobre os problemas cotidianos e concretizar as mudanças. Estas mudanças, desejadas pela escola, acontecerão somente quando todos os profissionais se conscientizarem que as relações precisam mudar - de coercitivas para cooperativas. 


\section{REFERÊNCIAS}

BARDIN, L. Análise de conteúdo. Lisboa: Edições 70, 1979.

DE VRIES, R.; ZAN, B. A ética na educação infantil: o ambiente sócio-moral na escola. Porto Alegre: Artes Médicas, 1998.

GIL, A. C. Métodos e técnicas de pesquisa social. 6. ed. São Paulo: Atlas, 2008.

IMBERNÓN, F. Formação continuada de professores. Porto Alegre: Artmed, 2010.

LA TAILLE, Y. Prefácio à edição brasileira. In: PIAGET, J. 0 juízo moral na criança. 1. ed. São Paulo: Summus,1994, p. 7-22.

MEMIN, M. S. S. Escola e educação moral. In: MONTOYA, A. O. D (org) Contribuições da Psicologia para a educação. Campinas: Mercado de Letras, 2007.

PIAGET, J. O juízo moral na criança. 1. ed. São Paulo: Summus,1994. [Obra originalmente publicada em 1932].

PICADO, J. R; ROSE, T. M. S. Acompanhamento de pré-escolares agressivos: adaptação na escola e relação professor-aluno. Psicologia Ciência e Profissão, v. 29, n. 1, p. 132-145, 2009, https://doi.org/10.1590/S1414-98932009000100011.

TARDELI, D. A. O respeito na sala de aula. Petrópolis: Vozes, 2003.

TOGNETTA, L. R. P.; VINHA, T. P. Quando a escola é democrática: um olhar sobre a prática das regras e assembleias na escola. Campinas: Mercado de Letras: 2007.

VINHA, T. P. O Educador e a Moralidade infantil: uma visão construtivista. Campinas: Mercado de Letras, Fapesp, 2000.

VINHA, T. P. Os conflitos interpessoais na relação educativa. Campinas, Faculdade de Educação, 2003. Tese (Doutorado em Educação), Universidade Estadual de Campinas, 2003.

VINHA, T. P; MANTOVANI DE ASSIS, O. Z. Considerações sobre as dificuldades do professor na construção de um ambiente cooperativo em sala de aula. Ícone, v. 11, n. 1, p. 69-94, 2005. 